\title{
KEPEMIMPINAN INSTRUKSIONAL KEPALA SEKOLAH
}

\author{
Sunardi*, Piter Joko Nugroho, Setiawan \\ Universitas Palangka Raya \\ *E-mail: Sunardi240695@gmail.com
}

\begin{abstract}
Abstrak: Penelitian kualitatif dengan rancangan studi kasus ini bertujuan untuk mendeskripsikan tentang Kepemimpinan Instruksional Kepala Sekolah di SMPN 2 Palangka Raya, dilihat dari: (1) Upaya yang dilakukan kepala sekolah dalam meningkatkan kualitas pembelajaran pada aspek guru dan siswa, (2) Dukungan stakeholder terhadap upaya kepala sekolah dalam meningkatkan kualitas pembelajaran, dan (3) Faktor pendukung dan kendala dalam implementasi kepemimpinan instruksional. Pengumpulan data dilakukan dengan metode wawancara mendalam, observasi partisipan, dan studi dokumentasi. Penetapan sumber data dilakukan dengan teknik purposive sampling. Analisis data dilakukan dengan menggunakan pola interaktif Miles dan Huberman (1994). Pengecekan keabsahan data dilakukan dengan menggunakan derajat kepercayaan (credibility) melalui teknik triangulasi baik sumber maupun metode. Hasil penelitian menunjukan bahwa: (1) Upaya yang dilakukan kepala sekolah dalam meningkatkan kualitas pembelajaran pada aspek guru dilakukan dengan melaksanakan workshop peningkatan kualitas pembelajaran, support guru untuk mengikuti kegiatan MGMP, supervisi akademik rutin kepada para guru; sedangkan pada aspek siswa dilakukan melalui pelaksanaan jam pelajaran tambahan dan kegiatan les privat, (2) Dukungan stakeholder terhadap upaya kepala sekolah dalam meningkatkan kualitas pembelajaran melalui kerjasama sinergis dengan pihak LPMP Provinsi Kalimantan Tengah, BSNP, Pengawas sekolah dan Komite sekolah, dan (3) Faktor pendukung dalam mengimplementasi kepemimpinan instruksional meliputi: tersedianya sarana para sarana penunjang proses pembelajaran, kinerja tenaga pendidik (guru) yang optimal, dan dukungan orang tua murid; Faktor kendala meliputi belum efektifnya pengelolaan sarana dan prasarana pembelajaran.
\end{abstract}

Kata Kunci: Kepemimpinan Instruksional, Kepala Sekolah, SMPN 2 Palangka Raya.

\begin{abstract}
This qualitative research with case study design aims to describe the Instructional Leadership of School Principals at SMPN 2 Palangka Raya, seen from: (1) Efforts made by principals in improving the quality of learning in aspects of teachers and students, (2) Stakeholder support for the efforts of principals schools in improving the quality of learning, and (3) Supporting factors and obstacles in the implementation of instructional leadership. Data collection is done by in-depth interviews, participant observation, and study documentation. Determination of data sources is done by using purposive sampling technique. Data analysis was performed using the interactive patterns of Miles and Huberman (1994). Checking the validity of the data is done by using a degree of credibility through both source and method triangulation techniques. The results showed that: (1) Efforts made by school principals in improving the quality of learning in the aspects of teachers were carried out by conducting workshops to improve the quality of learning, support teachers to take part in MGMP activities, routine academic supervision to teachers; while in the aspect of students is done through the implementation of additional learning hours and private tutoring activities, (2) Stakeholder support for the efforts of school principals in improving the quality of learning through synergic collaboration with the Central Kalimantan Province LPMP, BSNP, School Supervisors and School Committees, and (3) Supporting factors in implementing instructional leadership include: the availability of facilities to support the learning process, optimal performance of teaching staff (teacher), and support from parents of students; Constraint factors include ineffective management of learning facilities and infrastructure.
\end{abstract}

Keywords: Instructional Leadership, Principals, SMPN 2 Palangka Raya.

\section{PENDAHULUAN}

Kemajuan suatu negara ditopang dari berbagai macam aspek, antara lain ekonomi, politik, keamanan, dan pendidikan. Pendidikan menjadi salah satu penopang yang strategis untuk mewujudkan negara maju. Tentu saja pendidikan yang dimaksud adalah pendidikan yang bermutu. Pendidikan yang bermutu harus ditunjang dari berbagai aspek. Mulai dari kebijakan yang ditetapkan oleh pemerintah, pengelolaan 
pendidikan, sumber daya manusia, hingga sumber dana pendidikan (Juni, 2012).

Pendidikan yang bermutu dapat menghasilkan sumber daya manusia yang berkualitas dan produktif. Hal inilah yang mendorong suatu negara menjadi negara yang maju dan pesat dalam perkembangan ilmu pengetahuan serta teknologi. Kenyataan ini sejalan dengan tujuan Negara Indonesia. Menurut UndangUndang Dasar Negara Republik Indonesia Tahun 1945 Pasal 31 ayat (1) menyebutkan bahwa setiap warga negara berhak mendapat pendidikan. Sedangkan ayat (3) menegaskan bahwa pemerintah mengusahakan dan menyelenggarakan satu sistem pendidikan nasional yang meningkatkan keimanan dan ketakwaan serta akhlak mulia dalam rangka mencerdaskan kehidupan bangsa yang diatur dalam undang-undang. Untuk itu seluruh komponen bangsa wajib mencerdaskan kehidupan bangsa yang merupakan salah satu tujuan negara Indonesia.

Undang-Undang Nomor 20 Tahun 2003 Bab II Pasal 3 tentang Sistem Pendidikan Nasional (Sisdiknas) menyatakan bahwa pendidikan nasional bertujuan mengembangkan potensi peserta didik agar menjadi manusia yang beriman dan bertaqwa kepada Tuhan Yang Maha Esa, berakhlak mulia, sehat, berilmu, cakap, kreatif, mandiri dan menjadi warga negara yang demokratis dan bertanggung jawab. Pencapaian tujuan pembangunan nasional, pada hakikatnya adalah untuk meningkatkan kualitas manusia dan seluruh masyarakat Indonesia yang maju dan modern berdasarkan Pancasila.

Juni (2012) menyatakan salah satu jalan untuk mewujudkan peningkatan kualitas manusia adalah dengan peningkatan mutu pendidikan. Peningkatan mutu tersebut dapat dimulai dari lembaga formal pendidikan terkecil yakni sekolah. Sekolah merupakan organisasi yang kompleks dan unik, sehingga memerlukan tingkat koordinasi yang tinggi. Bersifat kompleks karena sekolah sebagai organisasi di dalamnya terdapat berbagai dimensi yang satu sama lain saling berkaitan dan saling menentukan. Sifat unik, menunjukkan bahwa sekolah sebagai organisasi memiliki ciri-ciri tertentu yang tidak dimiliki oleh organisasi-organisasi lain. Ciri-ciri yang menempatkan sekolah memiliki karakter tersendiri, di mana terjadi proses belajar mengajar, tempat terselenggaranya pembudayaan kehidupan manusia.

Sekolah sebagai lembaga pendidikan formal merupakan satuan pendidikan yang dirancang sedemikian rupa untuk mampu membentuk manusia yang berkepribadian dalam mengembangkan intelektual peserta didik dalam rangka mencerdaskan kehidupan bangsa. Sekolah suatu organisasi tempat penyelenggara pendidikan yang di dalamnya terdapat beberapa komponen yang saling berkaitan. Komponen tersebut yaitu: kepala sekolah, guru, pegawai, konselor, siswa, serta komite sekolah yang digolongkan sebagai sumber daya manusia yang saling bekerjasama untuk mencapai tujuan yang telah ditentukan. Hal ini sesuai dengan pendapat Fattah (2003) yang menyatakan sekolah sebagai wadah berlangsungnya proses pendidikan, memiliki sistem yang kompleks dan dinamis. Sekolah sebagai organisasi di dalamnya terhimpun kelompok-kelompok manusia yang masing-masing baik secara perseorangan maupun kelompok, melakukan hubungan kerjasama untuk mencapai tujuan. Selanjutnya dikatakan kelompok-kelompok manusia yangdimaksud, adalah sumber daya manusia yang terdiri dari: kepala sekolah, guru, tenaga administrasi kelompok peserta didik atau siswa, dan kelompok orang tua siswa. Oleh karena itu seharusnya sekolah mampu mencermati kebutuhan peserta didik yang bervariasi, agar mereka dapat mandiri, produktif, potensial dan berkualitas (Wahjosumidjo, 1999). 
Kepala sekolah sebagai pimpinan sekolah memikul tanggung jawab yang amat besar untuk memenuhi harapan dari berbagai pihak yang terkait. Dengan mengemban tugas pokok mencapai tujuan pokok pendidikan nasional yang telah dijabarkan dalam Undang-Undang Pendidikan Nasional, maka kepala sekolah dituntut untuk mampu mengarahkan, mengatur, memberi teladan kepada anak buahnya mencapai tujuan bersama yang telah ditetapkan.

Keberhasilan

dan

ketidakberhasilan sekolah mencapai tujuan ditentukan oleh berhasil tidaknya kepala sekolah mengatur atau mengelola sekolah atau seluruh potensi sekolah agar berfungsi optimal dalam mendukung tercapainya tujuan sekolah. Keefektifan (keberhasilan) sekolah juga akan terletak pada bagaimana dengan kepemimpinan kepala sekolah itu dalam merancang bangun organisasi sekolah (Nurkolis, 2002). Fakta umum telah menunjukkan bahwa, dalam mengelola sekolah diperlukan suatu rencana yang terinci, sehingga tidak terjadi pelaksanaan yang tumpang tindih, kurang koordinasi, komunikasi yang kurang interaktif, kurang motivasi, tidak transparan, kurang teliti, dan kurang dipahami didasarkan atas tugas dan fungsi organisasi. Kurang terprogramnya perencanaan sekolah, menjadikan prestasi kerja yang dicapai oleh sekolah tidak maksimal (Depdiknas, 2004).

Mulyasa (2011) menyatakan salah satu kekuatan efektif yang sangat menentukan keberhasilan sekolah atau lembaga pendidikan dalam mencapai tujuannya adalah kepemimpinan kepala sekolah. Kepemimpinan kepala sekolah menjadi penentu utama terjadinya proses dinamisasi sekolah. Efektifitas kepemimpinan pendidikan tidak dapat lepas dari beberapa aspek yang membangun terjadinya efektifitas kepemimpinan sehingga mutu pendidikan akan dapat dicapai. Kegagalan dan keberhasilan sekolah banyak ditentukan oleh kepala sekolah, karena kepala sekolah merupakan pengendali dan penentu arah yang hendak ditempuh oleh sekolah menuju tujuannya, lebih lanjut Mulyasa (2011) menyatakan tugas kepala sekolah bagai pimpinan angkatan bersenjata. Jika dalam angkatan bersenjata ada istilah "tidak ada prajurit yang bersalah", maka dalam pendidikan pun "tidak ada tenaga kependidikan yang bersalah". Selama ini justru sering kali disalahkan adalah guru padahal sebagian besar kesalahan dan dosa adalah kesalahan dan dosa kepala sekolah. Pentingnya kepemimpinan kepala sekolah ini juga didukung oleh pendapat Purwanto (1998) yang menyatakan bahwa kepala sekolah merupakan pemimpin pendidikan yang sangat penting. Dikatakan sangat penting karena lebih dekat dan langsung berhubungan dengan pelaksanaan program pendidikan tiap-tiap sekolah. Dapat dilaksanakan atau tidaknya suatu program pendidikan dan tercapai atau tidaknya tujuan pendidikan itu, sangat bergantung pada kecakapan dan kebijaksanaan kepala sekolah sebagai pemimpin pendidikan.

Dalam Permendiknas Nomor 13 Tahun 2007 dinyatakan untuk diangkat sebagai kepala sekolah seseorang wajib memenuhi standar kualifikasi dan kompetensi. Untuk standar kualifikasi meliputi yaitu, kualifikasi akademik (S1), usia maksimal 56 tahun, pengalaman mengajar sekurang-kurangnya 5 (lima) tahun, dan pangkat serendah-rendahnya III/c atau yang setara. Sedangkan kualifikasi khusus yaitu berstatus guru, bersertifikat pendidik, dan memiliki sertifikat kepala sekolah.

Berkaitan dengan kepemimpinan kepala sekolah, Gonton (1976) menyatakan telah banyak dilakukan penelitian yang mendalam dan membuktikan bahwa kepemimpinan kepala sekolah sangat menentukan keefektifan sekolah. Sulistyorini (2009) menyatakan bahwa sekolah yang efektif selalu dipimpin oleh kepala sekolah yang 
efektif. Hal tersebut membawa konsekuensi untuk menduduki jabatan kepala sekolah dituntut dipenuhi persyaratan, baik untuk kerja, administratif, akademik maupun kepribadian.

Stronge (1988) menyatakan untuk memperoleh hasil prestasi siswa yang baik perlu perubahan peran yang dramatis dari seorang kepala sekolah yang fokus pada isu-isu manajerial kepala sekolah yang fokus pada isu-isu pembelajaran (instructional). Moos Johansson dan Day (2010) dalam penelitiannya menyatakan kepala sekolah efektif dicirikan memiliki kepemimpinan pembelajaran yang kuat, yang fokus pada pengembangan standar kurikulum, monitoring perkembangan siswa, dan memaksimalkan waktu belajar.

Model kepemimpinan pembelajaran (instructional leadership) merupakan model kepemimpinan yang dapat mendorong meningkatnya prestasi siswa (Cotton, 2003). Kepemimpinan pembelajaran adalah kepemimpinan yang menekankan pada 5 aspek dalam penyelenggaraan sekolah, yaitu: (1) fokus pada pembelajaran, (2) membangun kerjasama, (3) analisa hasil pencapaian siswa, (4) pengembangan guru, dan (5) penyesuaian kurikulum, pengajaran, dan penilaian (Lunenburg dan Irby, 2006).

Beberapa contoh nyata sebagai bukti dari keberhasilan dari implementasi kepemimpinan instruksional pada SMPN2 Palangka Raya adalah berkaitan dengan keterlaksanaannya seluruh program dan aktivitas sekolah serta pencapaian prestasi antara lain: dalam bidang ekstra kurikuler seperti: prestasi karate, paskibraka, juara umum perlombaan drum band tingkat SMP/MTs di SMKN-5 Banjarmasin Kalimantan Selatan, prestasi atau keunggulan tersebut benar adanya dengan bukti nyata bahwa SMPN-2 Palangka Raya telah memiliki banyak piala-piala dan piagam yang diletakkan di dalam lemari dan tersedianya sarana penunjang pendidikan di sekolah seperti tempat ibadah, kantin sekolah, perpustakaan, lab. komputer, lab bahasa, lab. IPA, lapangan dan ruangan media.

Berdasarkan uraian konteks penelitian tersebut di atas tentang: (1) Pendidikan merupakan tolak ukur kemajuan suatu bangsa, (2) Sekolah merupakan institusi yang kompleks yang tidak akan menjadi baik dengan sendirinya tanpa upaya peningkatan tertentu, (3) Kepala sekolah merupakan salah satu komponen penting yang menentukan kualitas sekolah, (4) Berbagai studi menyimpulkan bahwa kepala sekolah yang menerapkan kepemimpinan yang berfokus pada peningkatan kualitas pembelajaran akan berdampak pada peningkatan kualitas dan capaian sekolah seperti peningkatan kualitas guru, siswa, maupun sekolah, (5) SMPN-2 Palangka Raya merupakan sekolah unggul di Kota Palangka Raya yang memiliki berbagai prestasi baik bidang akademik maupun non akademik dari siswanya sebagai dampak dari kualitas dan kinerja guru yang baik, maka penelitian tentang "Kepemimpinan Instruksional Kepala Sekolah di SMPN-2 Palangka Raya" penting untuk dilaksanakan.

\section{METODE}

Penelitian ini merupakan penelitian kualitatif dengan rancangan studi kasus. Kasus yang diangkat dalam penelitian ini tentang Kepemimpinan Instruksional Kepala Sekolah di SMPN-2 Palangka Raya. Metode pengumpulan data dilakukan dengan teknik: (1) wawancara mendalam (indepth interview), (2) observasi partisipan (participant observation), dan (3) studi dokumentasi (study of document). Penetapan informan yang menjadi sumber data dalam penelitian ini dilakukan dengan teknik purposive sampling. Analisis data dilakukan dengan menggunakan pola interaktif Miles dan Huberman (1994). Pengecekan keabsahan data yang diperoleh dilakukan dengan menggunakan derajat kepercayaan 
(credibility) melalui teknik triangulasi baik sumber maupun metode.

\section{HASIL DAN PEMBAHASAN}

\section{Upaya Kepala Sekolah dalam Meningkatkan Kualitas Pembelajaran Dilihat dari Aspek Guru dan Siswa}

a) Guru

Berdasarkan hasil temuan penelitian, diketahui bahwa upaya yang dilakukan kepala sekolah dalam meningkatkan kualitas pembelajaran yaitu: kepala sekolah mengadakan workshop peningkatan kualitas pembelajaran, dukungan penuh kepada guru untuk mengikuti kegiatan pelatihanpelatihan dalam kelompok MGMP serta supervisi rutin.

b) Siswa

Berdasarkan hasil temuan penelitian, diketahui bahwa upaya yang dilakukan kepala sekolah dalam meningkatkan kualitas pembelajaran yaitu: (1) siswa diadakan les privat, les tambahan, atau pelajaran tambahan di luar jam pelajaran tatap muka, (2) kegiatan les privat, les tambahan, atau pelajaran tambahan tersebut merupakan program oleh guru, yang pada dasarnya kegiatan tersebut merupakan instruksi dari kepala sekolah, arahan serta bimbingannya kepada tenaga pendidik (guru), (3) mata pelajaran yang di programkan yaitu mata pelajaran unggulan terutama untuk kelas IX menghadapi ujian nasional dan ujian akhir sekolah, sehingga tujuan utama sekolah yaitu menghasilkan tamatan atau output yang luar biasa, dan dapat bersaing pada dunia kerja.

Capaian yang diraih kepala sekolah tersebut merupakan dampak dari upaya yang telah dilakukan, sebagaimana diungkap Triatna (2015) sekolah berusaha untuk berprestasi dalam akademik maupun non akademik. Karena dari segi hasil (output) sekolah dikatakan bermutu tinggi, jika prestasi sekolah khususnya prestasi belajar peserta didik sesuai teori. Cotton (2003) menyatakan meningkatnya prestasi siswa dalam pembelajaran ditekankan pada 5 aspek dalam penyelenggaraan sekolah yaitu: (1) fokus pada pembelajaran, (2) membangun kerjasama, (3) analisa hasil pencapaian siswa, (4) pengembangan guru, dan (5) penyesuaian kurikulum, pengajaran, dan penilaian.

\section{Dukungan Stakeholder dalam Meningkatkan Kualitas Pembelajaran}

a) Lembaga Penjaminan Mutu Pendidikan (LPMP) dan Badan Standar Nasional Pendidikan (BSNP)

Berdasarkan hasil temuan penelitian, diketahui bahwa dukungan Stakeholder dalam meningkatkan Kualitas Pembelajaran: (1) mengadakan pertemuan langsung di sekolah dengan guru-guru dalam rangka melakukan survei, wawancara/interview dan supervisi secara langsung, (2) kegiatan tersebut dengan tujuan mencari solusi dan memecahkan masalah yang dialami tenaga pendidik (guru) dalam proses pembelajaran demi tercapainya kualitas pembelajaran yang optimal.

b) Pengawas sekolah/satuan pendidikan

Berdasarkan hasil temuan penelitian, diketahui bahwa dukungan Stakeholder dalam meningkatkan Kualitas Pembelajaran: (1) melaksanakan penilaian, pengolahan dan analisis data hasil belajar/ bimbingan siswa dan kemampuan guru, (2) memberikan arahan, bantuan dan bimbingan kepada guru tentang proses pembelajaran/ bimbingan yang bermutu untuk meningkatkan mutu proses dan hasil belajar/ bimbingan siswa, dan (3) melaksanakan penilaian dan monitoring penyelenggaran pendidikan di sekolah binaannya mulai dari penerimaan siswa baru, pelaksanaan pembelajaran, pelaksanaan ujian sampai kepada pelepasan lulusan/ pemberian ijazah, (4) melakukan pembinaan pengembangan kualitas sekolah, kinerja kepala sekolah, kinerja guru, dan kinerja seluruh staf sekolah, (5) melakukan evaluasi dan monitoring pelaksanaan program sekolah beserta pengembangannya, (6) Melakukan 
penilaian terhadap proses dan hasil program pengembangan sekolah secara kolaboratif dengan stakeholder sekolah, dan, (7) memberikan saran dan pertimbangan kepada pihak sekolah dalam memecahkan masalah yang dihadapi sekolah berkaitan dengan penyelenggaraan pendidikan.

c) Organisasi Masyarakat/Orang Tua Murid (Komite)

Berdasarkan hasil temuan penelitian, diketahui bahwa dukungan stakeholder dalam meningkatkan kualitas pembelajaran: (1) komite, pertemuan guru-guru dengan orang tua murid, (2) kelas orang tua yang dimana orang tua murid diundang ke sekolah untuk dapat hadir, memberikan motivasi, arahan, serta bimbingan kepada anak-anak mereka dan bisa mengetahui kegiatan-kegiatan apa saja yang dilakukan oleh anak-anak mereka di sekolah, kegiatan tersebut dilakukan selama sekali dalam satu bulan sekali.

Mengingat pentingnya dukungan dan kerja sama dengan lembaga-lembaga dan organisasi untuk meningkatkan kualitas pembelajaran maka Sediono, dkk. (2003) mengungkapkan bahwa peran serta stakeholder adalah kontribusi, sumbangan, dan keikutsertaan masyarakat dalam menunjang upaya peningkatan mutu lembaga pendidikan. Pada masa sekarang bahwa perencanaan, pelaksanaan, dan monitoring pendidikan melibatkan peran serta masyarakat. Kesadaran tentang pentingnya pendidikan yang dapat memberikan harapan dan kemungkinan lebih baik di masa yang akan datang, mendorong berbagai upaya dan perhatian seluruh lapisan masyarakat. Hal inilah yang melahirkan kesadaran peran serta masyarakat. Stakeholder pendidikan dapat diartikan sebagai orang yang menjadi pemegang dan sekaligus pemberi support terhadap pendidikan atau lembaga pendidikan. Dengan kata lain stakeholder adalah orang-orang, atau badan yang berkepentingan langsung atau tidak langsung terhadap kegiatan pendidikan di sekolah.

\section{Faktor Pendukung dan Penghambat dalam Peningkatan Kualitas Pembelajaran}

a. Faktor Pendukung

Berdasarkan hasil temuan

penelitian, diketahui bahwa faktor pendukung dalam peningkatan kualitas pembelajaran meliputi: (1) Sarana para sarana yang sudah memadai sebagai penunjang proses pembelajaran, seperti tersedianya layar proyektor/LCD yang sudah ada di setiap ruang kelas, (2) Kinerja tenaga pendidik (guru) yang optimal dalam proses belajar mengajar, (3) Adanya interaksi yang baik antara guru dengan siswa, guru dengan guru, guru dengan orang tua murid, (4) Dukungan orang tua murid terhadap pelaksanakaan kebijakan/peraturan sekolah.

b. Faktor Penghambat

Berdasarkan hasil temuan penelitian, diketahui bahwa faktor penghambat dalam peningkatan kualitas pembelajaran meliputi: (1) Sarana dan prasarana yang kurang terawat/terjaga, dan (2) perilaku siswa-siswi yang kadang sulit untuk diatur.

\section{SIMPULAN}

Berdasarkan hasil penelitian dan pembahasan yang telah diuraikan sebelumnya, dapat ditarik beberapa kesimpulan sebagai berikut:

1. Upaya Kepala Sekolah dalam Meningkatkan Kualitas Pembelajaran Dilihat dari Aspek Guru dan Siswa. Pada aspek Guru, upaya yang dilakukan kepala sekolah dalam meningkatkan kualitas pembelajaran yaitu dengan cara: (a) kepala sekolah melakukan atau mengadakan workshop, (b) melakukan pelatihanpelatihan, musyawarah guru mata pelajaran (MGMP), dan (c) melakukan supervisi akademik secara mandiri, dan dengan biaya sendiri (sekolah) guna untuk mengembangkan kemampuan 
guru-guru dalam mengelola proses pembelajaran dengan tujuan tercapainya tujuan pembelajaran dan kualitas pembelajaran yang efektif dan efisien. Pada aspek Siswa, upaya yang dilakukan kepala sekolah dalam meningkatkan kualitas pembelajaran yaitu dengan cara: kepala sekolah memberi arahan bimbingan kepada guru-guru untuk mengadakan, les privat, les tambahan atau pelajaran tambahan diluar jam pelajaran tatap muka biasanya kepada siswa-siswi, terutama untuk kelas 9 dengan mata pelajaran unggulan untuk ujian nasional dan ujian akhir sekolah, guna tercapainya tujuan pembelajaran yang berkualitas seperti apa yang telah diinginkan.

2. Dukungan dari stakeholder terhadap peningkatan kualitas pembelajaran, meliputi: (a) oleh Lembaga Penjaminan Mutu Pendidikan (LPMP) dan Badan Standar Nasional Pendidikan (BSNP) yaitu: dilakukan dengan adanya pertemuan dengan guru-guru dan warga sekolah dalam rangka melakukan survei, observasi, interview, dan supervisi kepada guru-guru, (2) dengan tujuan mencari solusi dan memecahkan masalah yang dialami guru-guru dalam proses pembelajaran demi tercapainya tujuan kualitas pembelajaran yang maksimal; (b) oleh pengawas sekolah, yaitu: melakukan pembinaan, pengembangan kualitas sekolah melalui kinerja kepala sekolah, kinerja guru, dan kinerja seluruh staf sekolah, (2) melakukan evaluasi dan monitoring, (3) melakukan penilaian terhadap proses dan hasil program pengembangan sekolah secara kolaboratif dengan stakeholder sekolah, dan (4) memberikan saran dan pertimbangan kepada pihak sekolah dalam memecahkan masalah yang dihadapi sekolah; dan (c) oleh orang tua murid melalui komite, dan paguyuban kelas orang tua murid, yang diadakan sebulan sekali.

3. Faktor pendukung dan penghambat dalam peningkatan kualutas pembelajaran di SMPN 2 Palangka Raya yaitu meliputi: (a) Faktor pendukung, meliputi: (1) sarana dan prasarana yang memadai, (2) kinerja tenaga pendidik (guru) yang optimal dalam proses belajar mengajar (3) adanya interaksi yang baik antara guru dengan siswa, guru dengan guru, orang tua murid dengan guru, dan (4) dukungan orang tua murid selalu mendukung peraturan yang dijalankan; dan (b) Faktor penghambat, meliputi: a) sarana dan prasarana yang kurang terawat/terjaga, dan b) perilaku siswa-siswi yang kadang sulit untuk diatur.

\section{UCAPAN TERIMA KASIH}

Ucapan terima kasih penulis sampaikan kepada para pihak Sekolah Menengah Pertama Negeri 2 Palangka Raya yang telah memberikan kemudahan akses untuk melaksanakan penelitian, serta Redaksi Equity in Education Journal (EEJ) yang telah memberikan kesempatan artikel saya dapat dimuat dalam jurnal ini.

\section{DAFTAR PUSTAKA}

Sujak, A. (2009). Kepemimpinan dan Manajer (Eksistensinya dalam Perilaku Organisasi). Jakarta: Rajawali Pers.

Fathoni, A. (2006). Metodologi Penelitian dan Teknik Penyusunan Skripsi. Jakarta: PT Rineka Cipta.

Fitri, A. Z. (2012). Pendidikan Karakter Berbasis Nilai dan Etika di Sekolah. Jogjakarta: Ar-Ruz Media.

Basrowi., \& Suwandi. (2008). Memahami Penelitian Kualitatif. Jakarta: Rineka Cipta.

Bush, R. (2003). Measuring Quality of Life Among Those with Type 2 in Primary Care. (online), diunduh pada tanggal 20 Juli 2018, dari 
http://www.uq.edu.au/helath/helathycomm/docs/Qol.pdf.

Cotton, K. (2003). Principals and Student Achievement. Virginia USA, ASCD. Diunduh pada tanggal 22 Juli 2018 dari:http://aktual asiddau.blogspot.com/2010/09/tug as-pokok-dan-fungsi-kepalasekolah.html

Daryanto. (2013). Kepala Sekolah sebagai Pemimpin Pembelajaran. Yogyakarta: Gava Media.

Mulyasa, E. (2001). Menjadi Kepala Sekolah Profesional. Bandung: PT. Remaja Rosdakarya.

Hallinger, P. (2003). Leadership for 21st Century Schools: From Instructional Leadership to Leadership for Learning. The Hong Kong Institute of Education, Diunduh pada tanggal 21 Oktober 2018, dari http://www.proquest.umi.com.

Hermino, A. (2014). Kepemimpinan Pendidikan di Era Globalisasi. Jakarta: Pustaka Pelajar.

Juni. D. W. (2012). Kepemimpinan Instruksional Kepala Madrasah dan Inovatif Guru terhadap Produktivitas Kerja Guru Madrasah Ibtidaiyah Se-Kecamatan Manis Renggo Klaten. Jurnal Ilmu Pendidikan. Diunduh pada tanggal 29 Oktober 2018, dari http://repo.iaintulungagung.ac.id/50 $/ 7 / . p d f$

Jalal, F. (2009). Reformasi Pendidikan Dalam Konteks Otonomi Daerah, Yogyakarta: Adicita Karya Nusa

Kompri. (2015). Manajemen Sekolah Orientasi Kemandirian Kepala Sekolah. Pustaka Pelajar.

Lunenburg, C., \& Irby, J. (2006). The Principalship; Vision toaction. Wadsworth: Cengangelearning. Diunduh pada tanggal 22 Oktober 2018, dari: http://lib.unnes.ac.id/21893/1/1401 411127-s.pdf.
Makawimbang, H. (2012). Kepemimpinan yang Bermutu. Bandung: Alfabeta

Arifin, M. (2012). Etika \& Profesi Kependidikan. Yogyakarta: Ar-Ruz Media.

Margono, S. (2009). Metodologi Penelitian Pendidikan. Jakarta: Rineka Cipta.

Miarso, Y. (2007). Menyemai Benih Teknologi Pendidikan. Jakarta: Kencana.

Miles, M., \& Huberman, A. M. (1992). Analisis Data Kualitatif: Buku Sumber Tentang Metode-Metode Baru. Jakarta: UI Press.

Moleong. L. J. (2010). Metode Penelitian Kualitatif. Bandung: Remaja Rosdakarya.

Moos, J., \& Day, O. C. (2011). How School PrincipalsSustain Over Time, International Perspective. UK. Springer. Diunduh pada tanggal 29 Oktober 2018, dari http://repo.iaintulungagung.ac.id/50/7/.pdf.

Mulyasa, E. (2011). Manajemen Berbasis Sekolah, Konsep, strategi dan Implementasi. Bandung: PT Remaja Rosdakarya

Nurdin, S. (2002). Guru dan Implementasi Kurikulum. Jakarta: Ciputat Pers.

Permendinas No. 13 Tahun 2007 tentang Standar Kepala Sekolah.

Rahmah, S. (2016). Mengenal Sekolah Unggulan.Diunduh pada tanggal 22 April 2019 darihttp://journal.uinalauddin.ac.id/index.php/InspiratifPendidikan/article/viewFile/3222/3 065.

Sediono, dkk., (2003). Paket Pelatihan Awal: Untuk Sekolah dan Masyarakat. Jakarta: NZAID.

Sugiyono. (2015). Metode Penelitian Pendidikan Pendekatan Kuantitatif, Kualitatif, dan $R$ \& D. Bandung: Alfabeta.

Sulistyorini. (2009). Evaluasi Pendidikan dalam Meningkatkan Mutu Pendidikan. Yogyakarta: TERAS. 
Equity in Education Journal (EEJ), Vol. 1, No. 1, Oktober 2019

Soutworth, G. (2002). Instructional Leadershipin Schools: Reflection and Empirical Evidence. Diunduh pada tanggal 10 Nopember 2018, dari:

https://core.ac.uk/download/pdf/82 042012.pdf.

Suharsaputra, U. (2016). Kepemimpinan Inovasi Pendidikan. Bandung: Refika Aditama.

Sugiyono. (2014). Memahami Penelitian Kualitatif. Bandung: Alfabeta.

Triatna, C. (2015). Perilaku Organisasi. Bandung: PT. Remaja Rosdakarya.
Usman, H., \& Raharjo, N. E. 2013. Strategi Kepemimpinan Pembelajaran Menyongsong Implementasi Kurikulum 2013. Jurnal Cakrawala Pendidikan. Diunduh pada tanggal 21 Oktober 2018, dari: https://journal.uny.ac.id/index.php/ cp.

Wahjosumidjo. (1999). Kepemimpinan Kepala Sekolah. Jakarta: Raja Grafindo Persada 